\title{
PRODUÇÃO DE ALFACE UTILIZANDO COBERTURA DO SOLO E PROTEÇÃO DAS PLANTAS
}

\author{
MULCHING AND ROW COVER IN LETTUCE CROP
}

\author{
Marie Yamamoto REGHIN ${ }^{1}$ \\ Claudio PURISSIMO ${ }^{1}$ \\ Anderson Luiz FELTRIM ${ }^{2}$ \\ Marco Aurélio FOLTRAN ${ }^{3}$
}

\begin{abstract}
RESUMO
O experimento foi realizado na Universidade Estadual de Ponta Grossa (PR), com o objetivo de testar materiais para a técnica da cobertura do solo, combinados ou não com a técnica da proteção de plantas. O delineamento experimental usado foi o de blocos casualizados, com cinco repetições. Os tratamentos seguiram esquema fatorial 3 (cobertura do solo com agrotêxtil preto, cobertura do solo com palha de arroz e solo nu) $\times 2$ (com e sem proteção das plantas). A cultivar de alface usada foi Veneza Roxa. A semeadura foi realizada em 02/05/01 e o transplante em 01/06/01. O agrotêxtil preto foi colocado nas parcelas e perfurado para o transplante das mudas. Após o transplante, colocou-se a palha de arroz picada numa camada de 2,0 $\mathrm{cm}$, assim como o agrotêxtil branco sobre as plantas, fixando-se as laterais com o próprio solo do canteiro. $\mathrm{Na}$ colheita, foram avaliados o número total de folhas, número de folhas queimadas por geada, altura da parte aérea, massa fresca e seca da planta, comprimento do caule e biomassa. Nesta ocasião, contou-se a população de espécies daninhas monocotiledoneas e dicotiledoneas, identificando-as e avaliando a respectiva massa seca. Observou-se que a técnica da proteção de plantas com agrotêxtil branco promoveu resposta positiva no cultivo da alface, com colheita mais precoce, de plantas com características comerciais desejáveis, mesmo na ocorrência de geada. Sem proteção houve diminuição de $34,62 \%$ na massa da planta, em função de perda por geada. A técnica de cobertura do solo com agrotêxtil preto foi eficiente no controle de plantas daninhas, promovendo aumento de $22,12 \%$ na massa fresca da planta, quando comparado com a cobertura do solo com palha de arroz.
\end{abstract}

Palavras-chave: Lactuca sativa L.; cobertura do solo, cultivo protegido, controle de plantas daninhas.

\begin{abstract}
An experiment was conducted in Ponta Grossa, Paraná, Brazil, in order to evaluate mulching materials and row cover with polypropylene. The experimental design was a randomized complete block with five replications. Treatments were arranged in a factorial scheme $3 \times 2$ (mulching with black polypropylene, rice straw and bare soil; row cover with white polypropylene and no row cover). Seeds were sowed in 05/02/01 and the plantlets transplanted in 06/01/01. Perforated black polypropylene mulch was placed on the plots before plantlet transplanting, while rice straw was placed after transplanting. White polypropylene was used as row cover. At harvesting, lettuce total leaf number, frost damaged leaves, plant height, stem lenght; plant fresh weight, plant dry matter of plant, and biomass, were evaluated. In addition, weed population and weed dry weight were assessed. Row cover with white polypropylene provided positive response on lettuce yield, with early harvest and high quality and commercial plant characteristics, even with frost occurrence. Frost damage in plots without row cover reduced plant weight by $34,62 \%$. Black poplypropylene mulch controlled weeds and provided $22,12 \%$ increase on plant weight compared to rice straw.
\end{abstract}

Key-words: Lactuca sativa L., mulching, protected cultivation, weed suppression.

\footnotetext{
${ }^{1}$ Engenheiros Agrônomos, Doutores, Professores Adjuntos. Departamento de Fitotecnia e Fitossanidade, UEPG, Ponta Grossa (PR). E-mail: freghin@convoy.com.br.

2 Bolsista de Iniciação Científica (CNPq).

${ }^{3}$ Acadêmico do Curso de Agronomia.
} 
REGHIN, M.Y. et al. Produção de alfaze utilizando a cobertura do solo...

\section{INTRODUÇÃO}

A alface é uma planta herbácea, pertencente à família Cichoriaceae e constitui o grupo de hortaliças folhosas mais popular, sendo consumida na forma de saladas. Possui caule diminuto, não ramificado, ao qual se prendem as folhas (FILGUEIRA, 2000).

Dependendo da cultivar, as plantas apresentam diferentes tipos comerciais, sendo os mais importantes: folhas lisas, com ou sem fechamento de cabeça; folhas crespas sem fechamento da cabeça; e folhas crocantes, que formam cabeça ou Americana. A coloração predominante varia de verde-claro a verde-escuro, mas algumas cultivares podem exibir coloração arroxeada nas folhas, devido à presença de pigmento antocianina (BLANCO et al., 1997).

No estado do Paraná, produz-se um volume de 42.744 toneladas, numa área de 2.308 hectares (SEAB/DERAL, 2001).

Em um mercado competitivo como o atual, os produtores necessitam de técnicas que propiciem uma comercialização diferenciada, com produto de melhor aparência e qualidade.

A técnica da cobertura do solo, também conhecida como "mulching", associada à proteção de plantas com polipropileno, pode ser uma alternativa viável para melhorar a produtividade e a qualidade da alface.

A cobertura do solo passou a ser utilizada mundialmente, em grande escala, com o surgimento dos filmes plásticos, tendo em vista seu baixo custo, a facilidade na aplicação e outras vantagens que trazem aos cultivos. No Brasil, é antigo o seu emprego na cultura do morango (GOTO, 1997).

Conforme Lamont (1993), com a técnica do "mulching", ocorre precocidade de produção, aumento da produtividade, menor compactação do solo e redução de plantas daninhas, entre outros benefícios. O "mulching" com o plástico de polietileno preto apresenta vários efeitos benéficos na produção de hortaliças em regiões temperadas, incluindo o aumento da temperatura do solo, conservação da umidade do solo, textura e fertilidade; controle de plantas daninhas, pragas e doenças (HANADA, 2001).

No entanto, ainda não são comuns dados sobre o uso do polipropileno preto como mulching. Trata-se de um material de fácil manuseio, podendo ser usado da mesma forma que o polietileno preto: cobre-se o canteiro, fixando-se nas laterais com o próprio solo; faz-se as perfurações no espaçamento definido e posteriormente, o transplante.

Materiais empregados na cultura da alface, que possibilitam a obtenção de produto sem presença de torrões entre as folhas são favoráveis, porque evitam a lavagem da planta colhida, que além de difícil, pode prejudicar sua conservação. O uso da cobertura do solo permite um mais produto limpo, com melhor qualidade.

Pereira et al. (2000) utilizaram cobertura com plástico preto, cobertura com plástico prata dupla face, transplante direto em canteiro com aveia dessecada e sem capina, cobertura com bagacilho, com tecido não tecido e testemunha. Os tratamentos com os plásticos foram os que tiveram menor incidência de plantas daninhas.

Por sua vez, o polipropileno branco tem o seu emprego principalmente na forma de cobertura direta sobre as plantas, como uma manta, sendo fixado nas laterais com o próprio solo. No Brasil, tem apresentado respostas favoráveis principalmente em relação à qualidade do produto obtido e precocidade na colheita, em cultivos como de pak choi (REGHIN et al., 2001), de morango (OTTO et al.,2000), e de alface (BOROSIC et al., 1994; OTTO et al., 2000). Em mandioquinha-salsa antecipou o tempo de colheita e aumentou o enraizamento das mudas (REGHIN et al.,2000). Além destas vantagens, diminuiu a incidência e a severidade de Alternaria sp. em pak choi (REGHIN et al., 2001) e na couve-chinesa (COLTURATO et al., 2001).

Entretanto, não se tem observado dados sobre o seu uso quando combinado com a técnica do mulching.

O presente trabalho teve como objetivo avaliar a técnica do "mulching" com diferentes materiais, combinado com a proteção de plantas, no cultivo da alface.

\section{MATERIAL E MÉTODOS}

O experimento foi conduzido na Fazenda-Escola da Universidade Estadual de Ponta Grossa (PR), em solo CAMBISSOLO HÁPLICO Tb Distrófico típi$\mathrm{co}$, e de textura argilosa. $\mathrm{O}$ delineamento experimental adotado foi o de blocos casualizados, com cinco repetições. Os tratamentos seguiram esquema fatorial 3 (cobertura do solo com agrotêxtil preto, com palha de arroz picada e solo nu) x 2 (com e sem proteção das plantas). A cultivar usada foi Veneza Roxa (SAKATA). Cada parcela teve 32 plantas distribuídas em quatro fileiras, no espaçamento $0,30 \times 0,30 \mathrm{~m}$. Fezse o preparo da área e encanteiramento, com enxada rotativa. Usou-se o polipropileno preto (agrotêxtil preto), com gramatura de $40 \mathrm{~g} \cdot \mathrm{m}^{-2}$ para a cobertura do solo, o qual foi colocado nas respectivas parcelas, preso nas laterais com o próprio solo e perfurados para o transplante. A palha de arroz picada foi colocada nas parcelas após o transplante, numa camada em torno de 2,0 cm de altura. O polipropileno branco (agrotêxtil branco), com gramatura de $20 \mathrm{~g} \cdot \mathrm{m}^{-2}$ foi colocado sobre as plantas, após o transplante e fixando-se as laterais com o próprio solo. A adubação orgânica foi realizada com esterco de gado $\left(5 \mathrm{Kg} \cdot \mathrm{m}^{-2}\right)$ e a química com a fórmula $5-25-10\left(0,10 \mathrm{Kg} \cdot \mathrm{m}^{-2}\right)$, antes do transplante. A semeadura foi realizada na data de 02/05/01, em bandejas de poliestireno expandido, usando-se o substrato Plantmax. O transplante foi conduzido quando as mudas atingiram $4-5$ foIhas definitivas, na data de 01/06/01. A umidade do solo foi mantida com irrigação por aspersão. Durante 
REGHIN, M.Y. et al. Produção de alfaze utilizando a cobertura do solo...

o desenvolvimento vegetativo, fez-se adubação nitrogenada em cobertura aos vinte dias do transplante, com uréia, na quantidade de $0,005 \mathrm{Kg} \cdot \mathrm{m}^{-2}$. Aos 64 dias após o transplante, nas parcelas com proteção de plantas e aos 70 dias nas parcelas sem proteção, foram colhidas seis plantas ao acaso das duas fileiras centrais, fazendo-se as seguintes avaliações: número total de folhas, número de folhas queimadas pela geada (incidente na madrugada do dia 28/07), altura da parte aérea, massa fresca da parte aérea, comprimento do caule e biomassa. A biomassa foi calculada através da relação entre a massa seca da parte aérea (secada em estufa a $60{ }^{\circ} \mathrm{C}$, até atingir peso constante), e a área ocupada por cada planta no espaçamento de 0,30 m. Além destas avaliações, usando um marcador quadrado de $0,25 \mathrm{~m}^{2}$, fez-se a contagem da população de plantas daninhas por parcela, separando-as em espécies monocotiledoneas e dicotiledoneas, identificando-as, pesando e anotando a massa seca de ambas.

Os dados obtidos foram submetidos a análise de variância e em casos de significância, para comparação das médias, usou-se o teste de Tukey no nível de $5 \%$ de probabilidade.

Os dados climáticos de temperaturas máximas e mínimas e precipitação pluvial, durante a condução do experimento, encontram-se na Figura 1.

$\mathrm{mm}$

${ }^{\circ} \mathrm{C}$

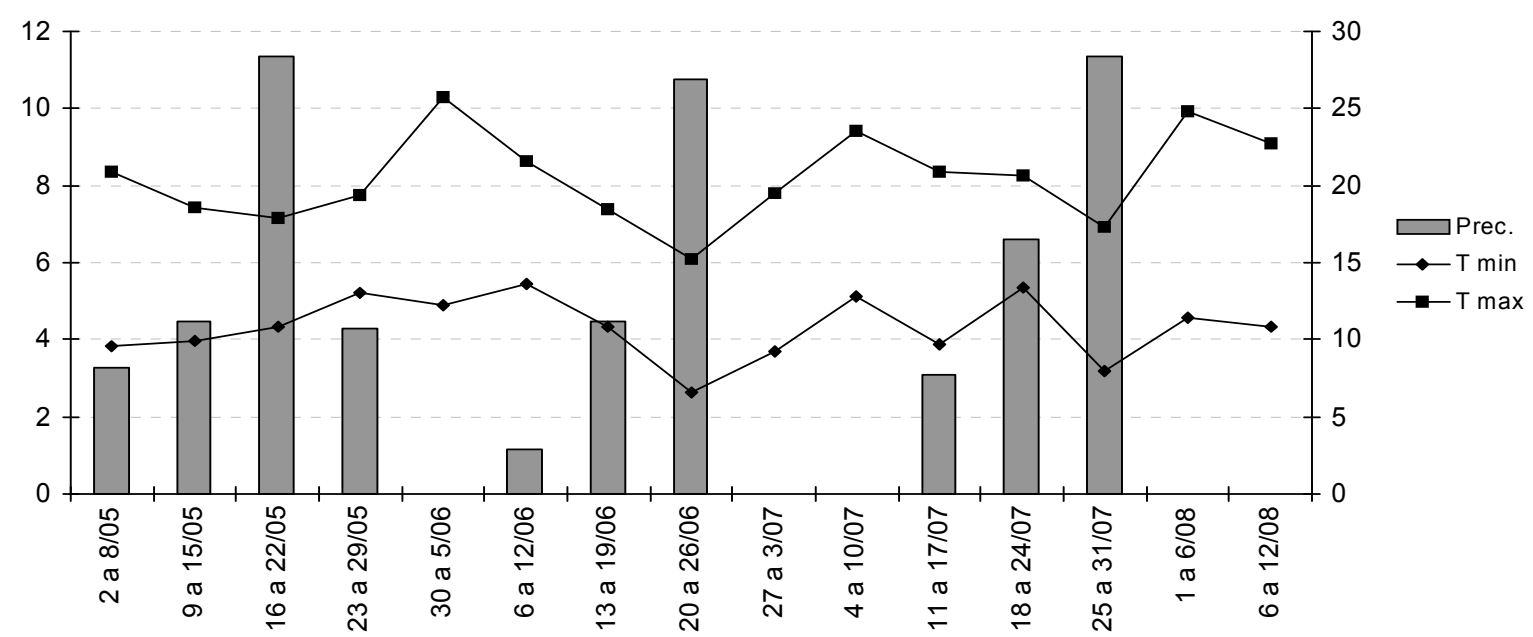

FIGURA 1 - Valores* médios semanais de temperaturas máximas e mínimas $\left({ }^{0} \mathrm{C}\right)$ precipitações semanais $(\mathrm{mm})$ registradas durante o período de realização do experimento. Ponta Grossa (PR), 2001. ${ }^{*}$ Dados fornecidos pelo IAPAR (Ponta Grossa, PR).

\section{RESULTADOS E DISCUSSÃO}

Não houve efeito significativo das interações entre cobertura do solo e proteção das plantas para nenhuma das características avaliadas (Tabelas 1 a 6 e Figuras 2 a 5 ).

Contando-se o número total de folhas (Tabela 1), não se observou efeito significativo da cobertura do solo, tampouco da proteção de plantas. No entanto, quando se fez a retirada das folhas que foram prejudicadas pela geada incidente no final do ciclo (Figura 1), observou-se que a proteção de plantas com agrotêxtil diminuiu o efeito destas (Tabela 2), apresentando apenas $7,08 \%$ de folhas com as bordas queimadas. Nas parcelas sem proteção, as plantas apresentaram $49,11 \%$ de queima nas folhas. Em relação à cobertura do solo, os percentuais observados não apresentaram diferença significativa.

A vantagem do emprego do agrotêxtil contra injúrias por geada foi relatada também em pak choi (REGHIN et al., 2001), quando o híbrido Canton teve a produção assegurada, antecipada e com melhor qualidade, na ocorrência de geada. Sem agrotêxtil, as plantas apresentaram bordas foliares queimadas e a colheita atrasou em uma semana. 
REGHIN, M.Y. et al. Produção de alfaze utilizando a cobertura do solo...

TABELA 1 - Número total de folhas de alface, cv. Veneza Roxa em função da cobertura do solo e da proteção de plantas. Ponta Grossa (PR), 2001.

\begin{tabular}{cccc}
\hline & \multicolumn{3}{c}{ Número Total de Folhas } \\
\hline Cobertura do solo & Com proteção de plantas & Sem proteção de plantas & Média* $^{*}$ \\
\hline Agrotêxtil preto & 24,83 & 23,93 & 24,38 a \\
Palha de arroz & 23,73 & 22,90 & 23,32 a \\
Solo nu & 23,87 & 23,37 & 23,62 a \\
\hline Média* $^{*}$ & $24,14 \mathrm{~A}$ & $23,40 \mathrm{~A}$ & \\
\hline
\end{tabular}

* Médias seguidas da mesma letra maiúscula na linha e minúscula na coluna, não diferem significativamente entre si no nível de $5 \%$ de probabilidade, pelo teste de Tukey.

TABELA2 - Porcentagem de folhas queimadas por geada, da alface cv. Veneza Roxa, em função da cobertura do solo e da proteção de plantas. Ponta Grossa (PR), 2001.

*Médias seguidas da mesma letra maiúscula na linha e minúscula na coluna, não diferem significativamente entre si no nível de $5 \%$ de probabilidade, pelo teste de Tukey.

Este resultado é de grande validade para produtores que cultivam folhosas no inverno em regiões como a de Ponta Grossa, com temperaturas mínima e máxima de 12 e $20^{\circ} \mathrm{C}$ e ocorrência de geadas freqüentes em todo o período.

Em relação à altura de plantas (Tabela 3 ), a cobertura do solo não afetou a mesma, não havendo diferença significativa. No entanto, o agrotêxtil branco sobre as plantas estimulou maior desenvolvimento em altura, quando comparada com plantas sem agrotêxtil. As plantas desenvolvidas sob o agrotêxtil, no período de inverno, apresentaram estiolamento, provavelmente devido à diminuição da radiação, com folhas de comprimento maior. Por sua vez, o caule também apresentou comprimento maior (Tabela 4), demonstrando que sob proteção, o desenvolvimento vegetativo é mais rápido, provavelmente em função do microclima propiciado pelo agrotêxtil, onde a temperatura se mantém sem grandes variações.

TABELA 3 - Altura da parte aérea da alface cv. Veneza Roxa, em função da cobertura do solo e da proteção de plantas. Ponta Grossa (PR), 2001.

\begin{tabular}{cccc}
\hline & \multicolumn{2}{c}{ Altura da oarte aérea $(\mathrm{cm})$} & Média* $^{*}$ \\
\hline Cobertura do solo & Com proteção de plantas & Sem proteção de plantas & 16,92 a \\
\hline Agrotêxtil preto & 19,43 & 14,41 & 16,38 a \\
Palha de arroz & 19,05 & 13,71 & 16,48 a \\
Solo nu & 19,06 & 13,92 & \\
\hline Média* $^{*}$ & $19,18 \mathrm{~A}$ & $14,02 \mathrm{~B}$ & \\
\hline
\end{tabular}

*Médias seguidas da mesma letra maiúscula na linha e minúscula na coluna, não diferem significativamente entre si no nível de $5 \%$ de probabilidade, pelo teste de Tukey. 
REGHIN, M.Y. et al. Produção de alfaze utilizando a cobertura do solo...

TABELA4 - Comprimento do caule da alface cv. Veneza Roxa, em função da cobertura do solo e da proteção de plantas. Ponta Grossa (PR), 2001.

\begin{tabular}{cccc}
\hline & \multicolumn{2}{c}{ Comprimento do caule $(\mathrm{cm})$} & Média* $^{*}$ \\
\hline Cobertura do solo & Com proteção de plantas & Sem proteção de plantas & 3,18 a \\
\hline Agrotêxtil preto & 3,73 & 2,63 & 2,97 a \\
Palha de arroz & 3,59 & 2,34 & 3,03 a \\
Solo nu & 3,45 & 2,62 & \\
\hline Média* $^{*}$ & $3,60 \mathrm{~A}$ & $2,53 \mathrm{~B}$ & \\
\hline
\end{tabular}

*Médias seguidas da mesma letra maiúscula na linha e minúscula na coluna, não diferem significativamente entre si no nível de $5 \%$ de probabilidade, pelo teste de Tukey.

O emprego da cobertura do solo teve efeito significativo sobre as plantas daninhas. Comparado ao solo nu, e à utilização de palha de arroz, o agrotêxtil preto reduziu significativamente a infestação tanto de espécies monocotiledoneas (Figura 2) quanto de dicotiledoneas (Figura 3).

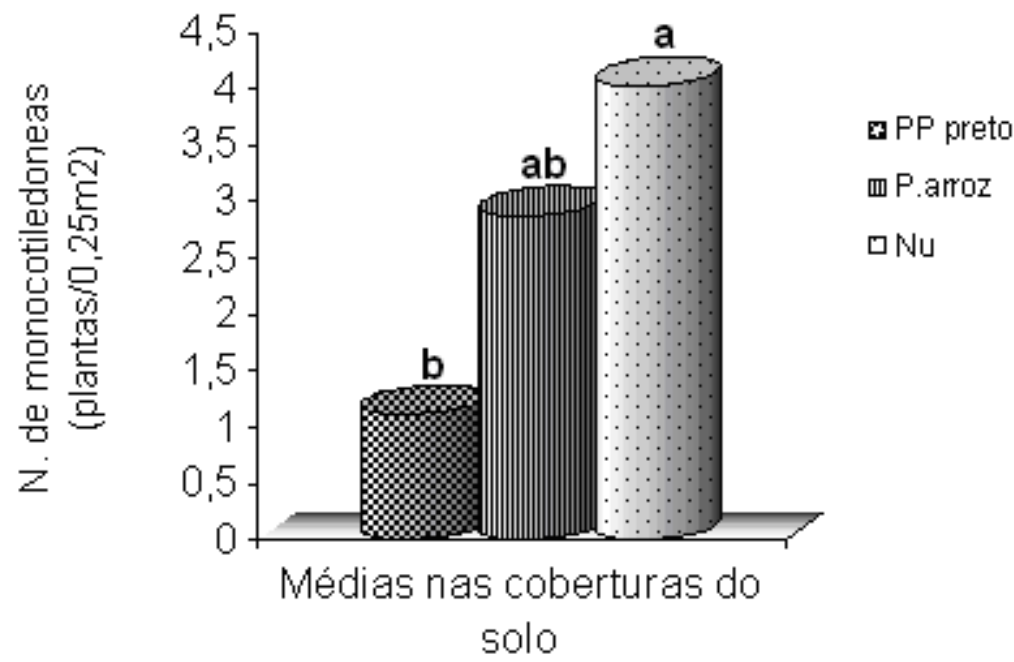

FIGURA 2 - Número de plantas daninhas monocotiledoneas (valores transformados para Öx+0,5) na cobertura do solo com agrotêxtil preto (PP preto), com palha de arroz e no solo nu, durante o cultivo da alface. Ponta Grossa (PR), 2001. 
REGHIN, M.Y. et al. Produção de alfaze utilizando a cobertura do solo...

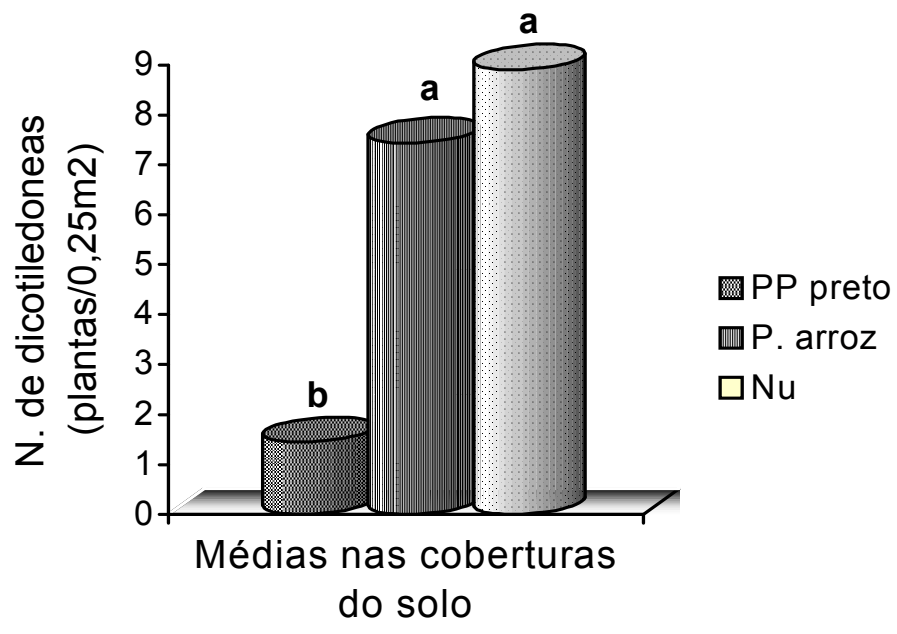

FIGURA 3 - Número de plantas daninhas dicotiledoneas (valores transformados para Öx+0,5) na cobertura do solo com agrotêxtil preto (PP preto), com palha de arroz e no solo nu, durante o cultivo da alface. Ponta Grossa (PR), 2001.

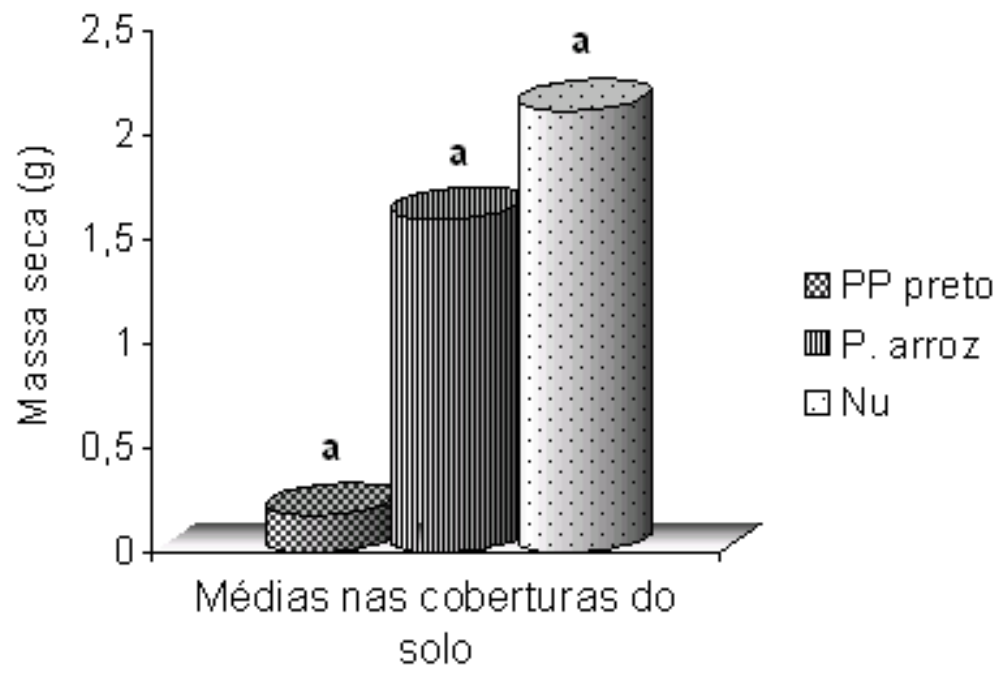

FIGURA 4 - Massa seca $(\mathrm{g})$ de plantas daninhas monocotiledoneas na cobertura do solo com agrotêxtil preto (PP preto), com palha de arroz e no solo nu durante o cultivo da alface. Ponta Grossa (PR), 2001. 


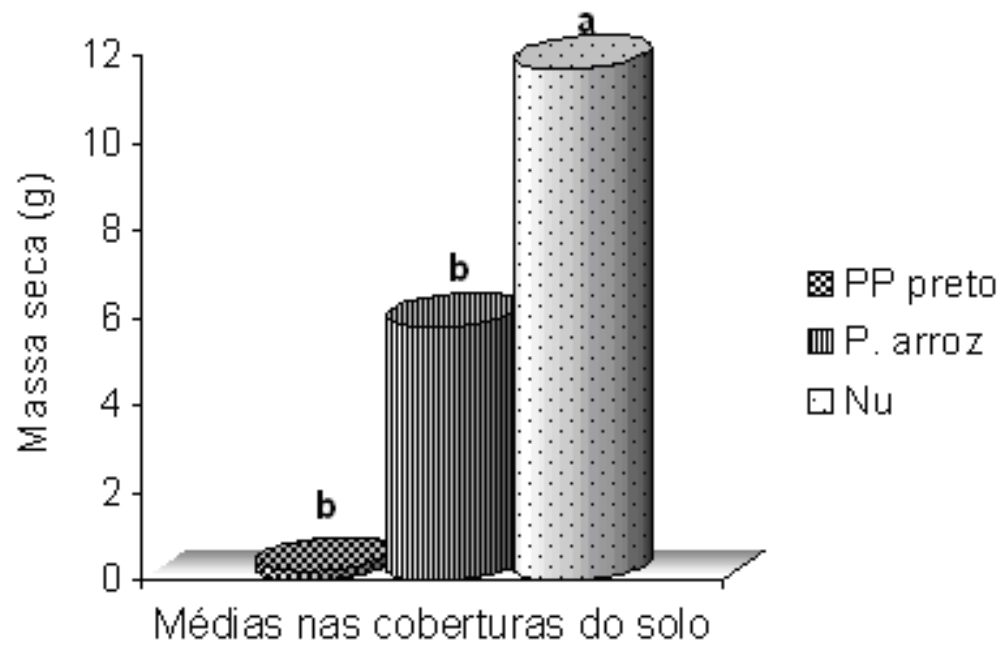

FIGURA 5 - Massa seca ( $\mathrm{g}$ ) de plantas daninhas dicotiledoneas na cobertura do solo com agrotêxtil (PP preto), com palha de arroz e no solo nu, durante o cultivo da alface. Ponta Grossa, PR, 2001.

A densidade populacional das espécies dicotiledôneas, representadas por picão branco (Galinsoga parviflora Cav.), erva-de-bicho (Polygonum persicaria L.), mentrasto (Ageratum conyzoides L.) e esparguta (Stelaria media (L.) Vill), predominou sobre as espécies monocotiledôneas, entre as quais se encontravam o capim-pé-de-galinha (Eleusine indica (L.) Gaertn.), capim-colchão (Digitaria horizontalis Willd.) e tiririca (Cyperus rotundus L.).

Na massa seca de espécies monocotiledoneas, os valores observados não apresentaram diferença estatística (Figura 4). Entretanto, os valores das espécies dicotiledoneas apresentaram significância, de acordo com o tipo de cobertura do solo. A massa seca das dicotiledôneas invasoras desenvolvidas sob cobertura de agrotêxtil preto, foi significativamente menor que aquelas desenvolvidas sob palhada de arroz e solo nu (Figura 5). Tal fato deve estar relacionado tanto a supressão no número quanto ao crescimento estiolado das invasoras sob cobertura do solo, refletindo em incapacidade de acumulação de biomassa seca.

A interferência das plantas daninhas na cultura da alface pode promover redução entre 30 a $45 \%$ na produtividade, quando a competição ocorre nos primeiros estádios de desenvolvimento da cultura. Cardona et al. (1977) relata que o período crítico de competição das plantas daninhas com a cultura da alface ocorre nos primeiros 20 dias após o transplante, com redução de 40 a $100 \%$ na formação e no peso da cabeça, à medida que se prolonga o período de competição.

Appezzato et al. (1983) observaram que o período crítico de competição ocorre entre a $2^{\mathrm{a}}$ e a $3^{\mathrm{a}}$ semana após o transplante e, para que não haja interferência no desenvolvimento e produtividade da cultura, o controle das plantas daninhas deve ser realizado durante as primeiras semanas após o transplante.

Silva et al. (1999), observou que o período de 14 dias de controle de ervas daninhas após o transplante, foi suficiente para que a cultura da alface expressasse seu potencial produtivo, podendo haver a convivência por até 28 dias sem redução significativa na produção. Desta forma, apenas uma eliminação das plantas daninhas, desde que realizada entre $14 \mathrm{e}$ 28 dias após o transplante, seria suficiente para prevenir a interferência.

Vários trabalhos sobre cobertura do solo com plástico de polietileno preto apontam como uma das vantagens, o controle das plantas daninhas (LAMONT, 1993; PEREIRA et al., 2000; HANADA, 2001).

$O$ agrotêxtil preto apresenta boas características para ser empregado na técnica da cobertura do solo, tendo demonstrado eficiência também no controle de plantas daninhas.

Trata-se de um material de fácil manuseio e aplicação, com porosidade, o que permite a passagem de água e por sua vez o uso da irrigação inclusive por aspersão. O polietileno preto, por ser impermeável, permite somente a irrigação por gotejamento.

O agrotêxtil preto na cobertura do solo apresentou respostas positivas também no cultivo do pak choi (REGHIN et al., 2001), mantendo a cultura no limpo durante todo o ciclo da cultura, enquanto nas parcelas sem cobertura do solo, houve necessidade de controle em duas oportunidades.

Por sua vez, a palha de arroz picada como cobertura do solo não apresentou resposta favorável, permitindo o desenvolvimento de várias espécies daninhas (Figuras 2 e 3 ).

Os valores da massa fresca da planta demons- 
REGHIN, M.Y. et al. Produção de alfaze utilizando a cobertura do solo...

tram que houve efeito significativo da proteção de plantas e da cobertura do solo (Tabela 5). Com proteção, houve superioridade na massa, em decorrência das plantas não terem sido prejudicadas pela geada. Sem a proteção, houve decréscimo de $32,64 \%$.

Quanto à cobertura do solo, houve superioridade da massa fresca quando se utilizou o agrotêxtil preto, diferindo significativamente da obtida na palha de arroz. $O$ agrotêxtil preto foi eficiente no controle de plantas daninhas, promovendo melhor desenvolvimento e produção de plantas com maior massa. $\mathrm{Na}$ palha de arroz, houve decréscimo da ordem de 18,12\% na massa fresca da planta e de $13,62 \%$ no solo nu, comparado ao agrotêxtil preto. Estes resultados confirmam que a presença de plantas daninhas interfere na formação e no peso da cabeça de alface. Os efeitos prejudiciais das plantas daninhas dependem da intensidade de infestação, com redução de até $61,6 \%$ na produção comercial (SILVA et al., 1999). Na palhada de arroz, o peso inferior observado provavelmente foi decorrente da manutenção do solo com temperatura mais baixa.

TABELA5 - Massa fresca da alface cv. Veneza Roxa, em função da cobertura do solo e da proteção de plantas. Ponta Grossa (PR), 2001.

\begin{tabular}{cccc}
\hline & \multicolumn{2}{c}{ Massa fresca da planta $(\mathrm{g})$} & Média* $^{*}$ \\
\hline Cobertura do solo & Com proteção de plantas & Sem proteção de plantas & $126,03 \mathrm{a}$ \\
Agrotêxtil preto & 153,68 & 98,38 & $103,20 \mathrm{~b}$ \\
Palha de arroz & 127,71 & 78,69 & $108,87 \mathrm{ab}$ \\
Solo nu & 127,49 & 90,26 & \\
\hline Média* $^{*}$ & $136,29 \mathrm{~A}$ & $89,11 \mathrm{~B}$ & \\
\hline
\end{tabular}

*Médias seguidas da mesma letra maiúscula na linha e minúscula na coluna, não diferem significativamente entre si no nível de $5 \%$ de probabilidade, pelo teste de Tukey.

TABELA6 - Biomassa das plantas de alface cv. Veneza Roxa, em função da cobertura do solo e da proteção de plantas. Ponta Grossa (PR), 2001.

\begin{tabular}{cccc}
\hline & \multicolumn{3}{c}{ Biomassa $\left(\mathrm{g} \cdot \mathrm{m}^{-2}\right)$} \\
\hline Cobertura do solo & Com proteção de plantas & Sem proteção de plantas & Média* $^{*}$ \\
\hline Agrotêxtil preto & 122,14 & 105,25 & $113,70 \mathrm{a}$ \\
Palha de arroz & 101,38 & 83,07 & $92,22 \mathrm{~b}$ \\
Solo nu & 99,36 & 97,70 & $98,53 \mathrm{ab}$ \\
\hline Média* & $107,63 \mathrm{~A}$ & $95,34 \mathrm{~B}$ & \\
\hline
\end{tabular}

*Médias seguidas da mesma letra maiúscula na linha e minúscula na coluna, não diferem significativamente entre si no nível de $5 \%$ de probabilidade, pelo teste de Tukey.

Os valores de biomassa acompanharam os resultados da massa fresca (Tabela 6), o que vem confirmar as respostas positivas da cobertura do solo com agrotêxtil preto e da proteção de plantas com agrotêxtil branco.

\section{CONCLUSÕES}

- As plantas cultivadas sob proteção com agrotêxtil branco tiveram menor percentagem de folhas danificadas pela geada, tendo produzido maior quantidade de massa fresca e biomassa;

- A cobertura do solo com agrotêxtil preto diminuiu a incidência de plantas daninhas na cultura da alface, permitindo um aumento na massa fresca média de $22,12 \%$;

- Na região dos Campos Gerais, no Estado do Paraná, a produção de alface no período de inverno sem utilização de proteção, pode ser comprometida pela ocorrência de geadas. 
REGHIN, M.Y. et al. Produção de alfaze utilizando a cobertura do solo...

\section{REFERÊNCIAS}

1 APPEZZATO, B.; TERAO, D.; CHRISTOFFOLETI, P. J. Competição de plantas daninhas com a cultura da alface (Lactuca sativa cv. Babá). O solo, Piracicaba, v. 75, n. 2, p. 5-10, 1983.

2 BLANCO, M.C.S.G.; GROPPO, G.A; TESSARIOLI NETO, J. Alface (lactuca sativa L.). In: Manual da Coordenaria de Assistência Ténica integral. Campinas. CATI, 1997. p.13-18. (Manual, 8).

3 BOROSIC, J.; ZUTIC, I.; MEBLIN, D. Spring crops of lettuce, carrot and pak-choi grown under direct covers. Reports of 13 International Congress of C.I.P.A., v. 1, 1994, 22p.

4 CARDONA, F.P.;ROMERO, M.C.E.; POLONIA, Z. Competencia de malezas en lechuga (Lactuca sativa var. capitata). Revista del Instituto Colombiano Agropecuário, Bogotá, v. 12, n. 4, p.407-20, 1997.

5 COLTURATO, A. B.; JACCOUD FILHO, D. de S.; OTTO, R. F.; GASPERINI, L. Avaliação da ocorrência de Alternaria brassicae em couve-chinesa cultivada sob agrotêxtil e ambiente natural na região de Ponta Grossa - Paraná. Horticultura Brasileira, v. 19, n. 2, p. 291, 2001. (Resumo).

6 EMBRAPA. Sistema Brasileiro de Classificação de Solos, Rio de Janeiro, p.412. 1999.

7 FILGUEIRA, F.A. R. Novo Manual de Olericultura: agrotecnologia moderna na produção e comercialização de hortaliças. Viçosa: Editora UFV, 2000. 402p.

8 GOTO, R. Plasticultura nos trópicos: uma avaliação técnico-econômica. Horticultura Brasileira, v. 15, p. 163-165, 1997. Palestra. Suplemento.

9 HANADA, T. The effect of mulching and row covers on vegetable production. Food and Fertilizer Technology Center, p.123, 2001. Disponível: http://www.agnet.org/library/abstract/eb332.html

10 LAMONT Jr., W.J. Plastic mulches for the production of vegetable crops. Hort Technology, v. 3, n. 1, p. 35-39, 1993.

11 OTTO, R. F.; REGHIN, M. Y.; TIMÓTEO, P.; PEREIRA, A. V.; MADUREIRA, A. Resposta produtiva de duas cultivares de morango cultivadas sob "não tecido" de polipropileno no município de Ponta Grossa-PR. Horticultura Brasileira, v. 18, p. 210-211, 2000. (Suplemento).

12 OTTO, R. F.; REGHIN, M. Y.; SÁ, G. D. Utilização do "não tecido" de polipropileno como proteção da cultura de alface durante o inverno de Ponta Grossa - PR. Horticultura Brasileira, v. 19, n. 1, p. 49-52, 2001.

13 PEREIRA, C. Z.; RODRIGUES, D. S.; GOTO, R. Ocorrência de plantas daninhas na cultura da alface em diferentes tipos de cobertura de solo no verão. Horticultura Brasileira, v. 18, p. 489-490. 2000. (Suplemento).

14 REGHIN, M. Y.; OTTO, R. F.; SILVA, J. B. C. da. "Stimulate Mo" e proteção com “Tecido não Tecido" no pré-enraizamento de mudas de mandioquinha-salsa. Horticultura Brasileira, v. 18, n. 1, p. 53-57, 2000.

15 REGHIN, M.Y.; OTTO, R.F.;VINNE,J. van der.; FELTRIN, A. L. Produção de pak choi sob proteção com "não tecido" de polipropileno. Horticultura Brasileira, v. 19, n. 2, p. 248, 2001. (Resumo).

16 REGHIN, M. Y.; DALLA PRIA, M.; FELTRIN, A. L.; VINNE, J. van der. Efeito da cobertura do solo e proteção das plantas de pak choi cultivadas com "não tecido" de polipropileno na ocorrência de doenças. Horticultura Brasileira, v. 19, n. 2, p. 266, 2001. (Resumo).

17 SECRETARIA DAAGRICULTURA E DO ABASTECIMENTO DO PARANÁ, DEPARTAMENTO DE ECONOMIA RURAL. Acompanhamento da situação agropecuária no Paraná. 92 p. junho/2001.

18 SILVA, A.C. Efeitos de diferentes períodos de controle e convivência de plantas daninhas na cultura da alface (Lactuca sativa L.). Maringá, 1999. 65p. Tese (Mestrado)- Universidade Estadual de Maringá. 